\title{
Práticas de barganha política por meio da execução orçamentária federal
}

\author{
Luis Henrique Teixeira Graton 1 \\ Carlos Alberto Grespan Bonacim ${ }^{2}$ \\ Sérgio Naruhiko Sakurai ${ }^{2}$ \\ 1 Faculdade de Filosofia, Ciências e Letras de Ituverava, Ribeirão Preto / SP - Brasil \\ 2 Universidade de São Paulo / Faculdade de Economia, Administração e Contabilidade, Ribeirão Preto / SP - Brasil
}

\begin{abstract}
O processo orçamentário brasileiro tem sido historicamente questionado pela suposta presença de barganha política na inclusão e na execução de emendas ao orçamento, fato que interfere nas premissas, nos critérios e nas práticas das escolhas alocativas. Este artigo, sustentado pela Teoria da Formação de Coalizões, investiga a existência de uma possível relação de barganha política entre os poderes Executivo e Legislativo no processo orçamentário na esfera federal. Tal pesquisa ocorre por meio da análise das execuções de emendas parlamentares singulares ao longo de cinco legislaturas (entre 2000 e 2017) e das decisões dos deputados na votação de projetos propostos pelo Executivo. Analisaram-se dados referentes à execução de emendas singulares, bem como aqueles concernentes à posição política do parlamentar com relação ao Executivo no instante da proposição das emendas. A metodologia envolveu técnicas econométricas que lidam com a correção do viés de seleção para avaliar a presença ou não da referida relação de barganha. Os resultados obtidos corroboram a hipótese de existência de barganha política entre os poderes Executivo e Legislativo, pois o parlamentar com maior aporte de execução de suas emendas singulares foi aquele que, além de ter exercido apoio ao Executivo através de votos favoráveis aos projetos enviados ao congresso nacional, era de fora da coligação de governo, alvo do Executivo na formação do quorum mínimo para a aprovação de seus projetos.
\end{abstract}

Palavras-chave: presidencialismo de coalizão; processo orçamentário; emendas singulares; barganha política.

\section{Prácticas de regateo político mediante la ejecución presupuestaria federal}

El proceso presupuestario brasileño ha sido históricamente cuestionado por la supuesta presencia de regateo político en la inclusión y ejecución de enmiendas al presupuesto, hecho que interfiere con las premisas, criterios y prácticas de las decisiones distributivas. Este artículo, apoyado en la Teoría de la Formación de Coaliciones, investiga la existencia de una posible relación de regateo político entre los poderes Ejecutivo y Legislativo en el proceso presupuestario a nivel federal. Dicha investigación se da a través del análisis de las ejecuciones de enmiendas parlamentarias singulares en cinco legislaturas (entre 2000 y 2017) y de las decisiones de los diputados en la votación de proyectos propuestos por el Ejecutivo. Se analizaron datos referentes a la ejecución de enmiendas singulares, así como los referentes a la posición política del parlamentario frente al Ejecutivo al momento de la proposición de las enmiendas. La metodología involucró técnicas econométricas que tratan la corrección del sesgo de selección para evaluar la presencia o ausencia de la referida relación de regateo. Los resultados obtenidos corroboran la hipótesis de existencia de regateo político entre los poderes Ejecutivo y Legislativo, ya que el parlamentario con mayor aporte de ejecución de sus enmiendas singulares fue quien, además de haber apoyado al Ejecutivo a través de votos a favor de los proyectos remitidos al Congreso Nacional, era ajeno a la coalición de gobierno, objetivo del Ejecutivo en la formación del quórum mínimo para la aprobación de sus proyectos.

Palabras clave: presidencialismo de coalición; proceso presupuestario; enmiendas singulares; regateo político. 


\section{Political bargaining practices through federal budget execution}

The Brazilian budgetary process has historically been questioned based on the alleged use of political bargaining in the inclusion and implementation of amendments from deputies to the executive's budget, which affects the principles, criteria, and practices of allocative choices. Supported by the theory of coalition formation, this article examines a possible political bargaining relationship between the executive and legislative branches in the budgetary process at the federal level. The study analyzed the execution of amendments from deputies over five mandates (between 2000 and 2017) and the deputies' votes on projects proposed by the executive. Data regarding the execution of singular amendments were also analyzed, together with information concerning the deputies' political position toward the executive when proposing amendments. Econometric techniques were employed to correct selection bias, assessing the presence of political bargaining. The results corroborate the hypothesis that there is political bargaining in the relationship between the executive and legislative branches in Brazil. The deputy who had more of their amendments executed by the government was also the one that voted with the government in the bills sent from the executive to the legislative, even though they were not part of the governing coalition in the Congress. Therefore, the executive targeted deputies who were not part of the governing coalition to increase the number of votes in Congress.

Keywords: coalition presidentialism; budgeting process; singular amendments; political bargaining.

\section{INTRODUÇÃO}

Denúncias de corrupção, pedido de impeachment de presidente da República e abertura de processos investigativos, como as Comissões Parlamentares de Inquérito (CPI), entre outros escândalos recentes, têm direcionado a atenção sociedade brasileira e da academia à nossa, senão frágil, questionável estabilidade política. A evidente crise de governabilidade ocorre em todas as esferas de poder e, por vezes, gera embates entre os três poderes e judicialização das decisões e dos atos administrativos: do processo de impeachment, em 2016, que cassou o mandato da presidente Dilma Rousseff, passando pelas denúncias ao Supremo Tribunal Federal (STF) do presidente Michel Temer, as quais levaram a exaustivas sessões na Câmara dos Deputados e culminaram em sua absolvição em 2017, até as recentes crises e os embates públicos entre o presidente Jair Bolsonaro e tais instâncias.

A crise e o conturbado momento político brasileiro têm propiciado elementos que instigam importantes discussões sobre os mecanismos utilizados para a manutenção da governabilidade, bem como da harmonia (ou não) entre os três poderes. A perspectiva da Teoria da Formação de Coalizões aborda os mecanismos de governo para a manutenção da coalizão por meio de partidos políticos (Figueiredo \& Limongi, 2006; Limongi \& Figueiredo, 1998; Santos, 2002). Dessa maneira, o Poder Executivo conseguiria governabilidade ao viabilizar suas estratégias e seus programas de governo (pois depende da autorização do Legislativo na aprovação do orçamento), fortalecendo deputados aliados mais próximos ideologicamente, bem como recursos, via execução de emendas, para os congressistas mais distantes (Pereira \& Orellana, 2009).

Temos, assim, uma possível discricionariedade atribuída ao Poder Executivo na realização de despesas não obrigatórias (Gontijo, 2010; Kanayama, 2009; Lima \&Viana, 2016). Somada ao interesse do Poder Legislativo na política clientelista, por meio da qual consegue executar emendas que beneficiem suas principais bases eleitorais (Kang, 2018; Pereira, 2000; Weingast, Shepsle, \& Johnsen, 1981), tal falha cria a possibilidade da ocorrência de barganha política entre os referidos poderes. A barganha política pode ser entendida como uma concessão de favores por um indivíduo que almeja 
vantagens ou privilégios que satisfaçam seus principais interesses. Trazendo para a linguagem do setor público, tais interesses resumem-se, então, à manutenção do poder do agente político.

O fenômeno abordado neste artigo pode ser retratado no processo orçamentário público do na esfera federal na seguinte situação: o Poder Executivo, almejando manter ou até mesmo aumentar a unidade de sua coalizão (Pereira \& Mueller, 2002; Riker, 1962; Scartacini \& Crain, 2001), busca executar emendas parlamentares em troca de apoio a seus projetos votados no Congresso Nacional (Bertholini \& Pereira, 2017; Martins, 2016; Ravanelli, Costa, \& Bonacim, 2012). Muito embora tais estudos tenham abordado partes desse fenômeno, a proposta do artigo não é caracterizar o comportamento do Executivo, algo já tratado pela literatura existente, mas, sim, o dos congressistaschave para garantir a execução dos projetos do Poder Executivo e a consequente manutenção de sua coalizão, materializando a barganha política.

Portanto, sustenta-se a hipótese de que, em busca de governabilidade (reunida na necessidade de aprovação de projetos, da formação e de gerenciamento de coalizão e do aumento de governabilidade), o Poder Executivo utiliza-se da discricionariedade na execução de emendas parlamentares com o objetivo de implementar seus projetos e reformas.

Assim, o estudo tem como objetivo encontrar evidências da barganha política, na esfera federal, entre o Poder Executivo e o Poder Legislativo, por meio do processo de execução de emendas parlamentares. Para tanto, a pesquisa analisou dados de execução orçamentária e dados relativos aos parlamentares referentes às cinco legislaturas formadas por governos e coalizões diferentes. Busca-se identificar, também, o quanto um maior apoio político altera em montantes monetários despendidos a execução das emendas daqueles parlamentares que optam por participar dessa relação.

Os resultados obtidos reforçam a ideia de que a discricionariedade do Poder Executivo se une ao interesse clientelista de sua coalizão para a aprovação de projetos e a execução de emendas. Isso porque o parlamentar com maior aporte de execução de suas emendas singulares ao longo do período estudado foi aquele que, além de ter exercido apoio ao Executivo por meio de votos favoráveis aos projetos enviados ao Congresso Nacional, era de fora da coligação de governo. Esse fato reforça a tese de que tais congressistas se tornam alvo do Executivo na formação do quorum mínimo para a aprovação de seus projetos.

\section{0 QUE ESTÁ POR TRÁS DO FENÔMENO: A TEORIA DA FORMAÇÃO DE COALIZÕES}

Conforme já mencionado, a discricionariedade do Executivo em poder executar ou não demandas dos parlamentares somada à ausência de mecanismos de governança corporativa no processo orçamentário permite a ocorrência de barganha política entre o Executivo e o Legislativo na execução de emendas orçamentárias. Em tal situação, ambos buscam satisfazer seus interesses e preservar seu status político em potencial detrimento do interesse dos cidadãos (Lima \& Viana, 2016; Martins, 2016).

Nesse contexto, emerge um fator importante para o Executivo, fundamental para sua governabilidade diante de um Legislativo fragmentado e multipartidário - qual seja, a formação e o gerenciamento de uma base apoiadora legislativa. Esta será facilitadora na aprovação de seus projetos que, certamente, passarão por sua apreciação. Tal base denomina-se coalizão (Figueiredo \& Limongi, 2006; Santos, 2002).

A necessidade, por parte dos governos, de constituir coalizões e a consequente busca de aprovação de seus projetos perante os parlamentares, permite analisar o fenômeno de barganha 
política aqui abordado, do qual emerge a Teoria da Formação de Coalizões - doravante TFC (Limongi \& Figueiredo, 1998).

Originalmente alicerçada em estudos de governos parlamentares, essa teoria já foi empregada em estudos que tratam de governos não só presidencialistas, mas também multipartidários, como é o caso do Brasil (Bertholini \& Pereira, 2017; Chaisty, Cheeseman, \& Power, 2014; Cheibub, Przeworski, \& Saiegh, 2004).

Procurando não só formar uma coalizão mínima vencedora, mas também formar coalizões grandes o bastante para garantir vitórias legislativas (Riker, 1962), observa-se que a necessidade de o Executivo manter a unidade e a disciplina pode tornar o processo de se governar (excessivamente) dispendioso (Pereira \& Mueller, 2002). Com isso, são agregados mais custos para o chefe de governo, refletidos até mesmo na execução do orçamento público, objeto deste estudo.

Como se não bastasse a dificuldade do Executivo em gerenciar sua coalizão (dado o multipartidarismo característico na política brasileira) e, por isso, precisar utilizar do que estiver a seu alcance para ter liberdade para executar suas políticas, outro aspecto importante do fenômeno analisado é o já mencionado interesse dos membros do Legislativo na política clientelista. Em particular, preocupados prioritariamente em manter seu futuro eleitoral e sua carreira política, tais agentes priorizam a proposição e a execução de emendas que beneficiem suas principais bases eleitorais. Emerge, desse modo, um ponto em comum entre os Poderes Executivo e Legislativo federal: o fato de ambos almejarem a manutenção de poder, independentemente de seus motivos intermediários.

Capellini (2018) propõe um modelo teórico que explica a relação entre Poderes Executivo e Legislativo na distribuição dos recursos públicos. Esse modelo leva em conta a incerteza quanto ao comportamento dos congressistas nas votações no Congresso e supõe que as negociações entre os referidos poderes são realizadas em três níveis: atacado; varejo; e sob demanda.

No atacado, prevalecem as estratégias de governo para a formação de alianças partidárias e a distribuição de cargos de poder, notadamente em ministérios. Segundo Capellini (2018), os congressistas que atuam nesse nível tendem a ser mais fiéis a seus partidos e mais disciplinados nas votações, gerando menos incerteza ao Executivo. Já os congressistas que atuam no varejo não só tendem a apresentar um comportamento menos fiel a seus partidos (maior incerteza sobre o voto), mas também são mais propensos a mudar de partido. Isso pode dificultar ainda mais a previsão de seu comportamento nas votações.

A princípio, conjectura-se não ser possível afirmar que um ou outro tipo de negociação sejam mais vantajosos para otimizar a obtenção dos recursos, porém, teoricamente, os congressistas que negociam no varejo dependem dos (ou ambicionam mais) recursos via liquidação de emendas parlamentares, pois, estando fora da distribuição de cargos, é sua moeda de troca. Por fim, indo além das negociações no atacado e no varejo, o terceiro nível envolveria a venda de votos sob demanda, que ocorreria em situações pontuais envolvendo o apoio de determinado parlamentar condicionado ao recebimento de uma recompensa específica, possivelmente sob a forma de liquidação de emendas.

Assim como existem níveis de negociação da distribuição de recursos, existem níveis de interesse do governo nas votações. Compreender a relevância de cada votação é fundamental para que o congressista se posicione adequadamente na arena de barganha política. Os congressistas que negociam no atacado não fazem essa diferenciação, mas os congressistas que atuam no varejo podem diminuir seu apoio ao governo em determinadas votações quando estas representarem potencial perda de seu 
capital político. Esse risco para o congressista é identificado, por exemplo, em votações de denúncias contra o presidente, devido à grande comoção social gerada.

Portanto, salvo a possibilidade de voto por afinidade ideológica ou programática, o congressista que atua no varejo tende a diminuir seu apoio à coalizão de governo em votações que representem risco ao presidente. No entanto, isso pode mudar caso ele seja cooptado, o que o levaria para a arena de barganha política sob demanda.

Desse modo, a negociação no varejo deve se refletir em queda na aderência à coalizão em situações de perda de força do presidente, enquanto a propensão à cooptação deve espelhar o aumento do apoio à coalizão de governo nessas votações. Já os congressistas que atuam no atacado serão impactados por essas votações, conforme a dinâmica das alianças partidárias.

Dado o modelo teórico apresentado anteriormente, há as seguintes hipóteses a serem testadas neste estudo:

- $\mathrm{H}_{0}$ : Parlamentares que exercem apoio ao Executivo em votações no Congresso não são mais beneficiados em execuções de suas emendas com relação aos demais.

- $\mathrm{H}_{1}$ : Parlamentares que exercem apoio ao Executivo em votações no Congresso são mais beneficiados em execuções de suas emendas com relação aos demais.

\section{PARTICULARIDADES DO ORÇAMENTO PÚBLICO BRASILEIRO}

O processo de construção do orçamento público brasileiro, como um dos principais instrumentos administrativos do Poder Executivo (em nível de programação, execução e controle), vem constantemente sofrendo mudanças em busca do aprimoramento de sua utilidade e da mitigação de falhas que prejudicam o atendimento das necessidades da sociedade. Com a promulgação da Constituição Federal, criou-se a obrigatoriedade de as várias esferas do governo adotarem instrumentos inovadores de planejamento e orçamento (Constituição da República Federativa do Brasil de 1988). Dessa obrigatoriedade, por meio do artigo 3o da Lei Complementar 101/2000 (Lei de Responsabilidade Fiscal), incumbiu-se o Poder Executivo da elaboração do Plano Plurianual (PPA), no primeiro ano de um determinado mandato, instituindo-se nele, de forma regionalizada, todas as diretrizes, objetivos e prioridades estratégicas de longo prazo do governo federal. Posteriormente, esse plano é encaminhado ao Congresso Nacional, que tem até a data de 15 de dezembro para apreciar, emendar, aprovar e enviar novamente ao Executivo para sua sanção.

A partir daí, o PPA passa a ter, então, a duração de quatro anos, a partir do segundo ano do mandato do chefe do Poder Executivo até o primeiro ano do próximo mandatário, induzindo uma continuidade do processo de planejamento do setor público. Além desse plano, outro instrumento foi implementado com a nova Constituição de 1988, como a Lei das Diretrizes Orçamentárias (LDO), que é encaminhada anualmente pelo Poder Executivo ao Legislativo e que, se aprovada, estabelece as metas e prioridades fiscais do governo. Assim, junto com o PPA, a LDO serve de base para definir as prioridades na elaboração do Projeto de Lei Orçamentária Anual (PLOA) do ano fiscal corrente.

Depois de serem elaborados os orçamentos com as propostas dos ministérios, em que se definem parâmetros e metas pela Secretaria de Orçamento Federal do Ministério de Planejamento, Orçamento e Gestão, o PLOA - com as estimativas de receitas e determinações de despesas e seus limites 
estabelecidos aos programas por cada um dos ministérios e órgãos públicos -, há o encaminhamento ao Congresso Nacional. Com a aprovação, segue-se para a sanção do Executivo (Giacomoni, 2008).

Ao serem encaminhadas ao Congresso Nacional, as matérias orçamentárias são analisadas, discutidas e apreciadas pela Comissão Mista de Planos, Orçamentos Públicos e Fiscalização (CMO). ${ }^{1}$ Tal comissão é formada por 40 parlamentares, sendo 30 deputados e 10 senadores.

No âmbito da apreciação pela $\mathrm{CMO}$, incumbida de deliberar sobre os instrumentos orçamentários (PPA, LDO e PLOA), bem como sobre alterações com créditos adicionais, o PLOA recebe, então, emendas propostas pelos membros do Congresso. Estas devem ser compatíveis com o PPA e a LDO e respeitar os prazos e limites que regem a funcionalidade da Comissão. Analisada pelo Legislativo, como qualquer outra lei, a Proposta de Lei Orçamentária segue para a sanção do chefe do Poder Executivo sendo, então, promulgada e publicada para a execução no ano seguinte.

As emendas dos parlamentares anexadas ao Plano Orçamentário podem ser propostas tanto coletivamente quanto individualmente. Estas, inicialmente, eram limitadas em cinquenta por parlamentar ${ }^{2}$ sendo posteriormente reduzidas para vinte, ${ }^{3}$ tendo sofrido recentemente novas limitações com a Emenda Constitucional (EC) 86.

Com a finalidade de tornar o processo de execução do orçamento público menos discricionário, a Emenda Constitucional 86, em vigor desde março de 2015, alterou os artigos 165 e 166 da própria Constituição Federal, ao vincular 50\% do total de emendas à destinação obrigatória a programas na área da saúde, estabelecendo um limite de $1,2 \%$ da receita corrente líquida ${ }^{4}$ para o gasto com as emendas parlamentares (Martins, 2016). No entanto, segundo Greggianin e Silva (2015), a EC 86/2015 também tem suas limitações, pois estabelece a não obrigatoriedade da execução de emendas parlamentares, caso haja impedimento de ordem técnica e legal que impossibilite a execução total ou parcial das programações. Ao priorizar o cumprimento das metas fiscais, tal impedimento propicia margem para a execução discricionária das despesas orçamentárias e coloca o Executivo em posição favorável na relação de barganha política com o Legislativo.

Ainda, e a fim de garantir a impositividade orçamentária, foi promulgada a EC 100, que alterou os artigos 165 e 166 da Constituição Federal (CF) de 1988. Essa alteração passou a garantir, em seu $\$ 12$, a execução de "emendas de iniciativa de bancada de parlamentares de Estado ou do Distrito Federal, no montante de até $1 \%$ (um por cento) da receita corrente líquida realizada no exercício anterior". Antes da referida EC, a possibilidade de uma emenda ao orçamento se tornar impositiva recaía apenas sobre as emendas individuais. Contudo, tal entendimento foi alterado após sua promulgação.

Dessa forma, apesar de todas as negociações e trâmites para aprovação e sanção das emendas, não havia, até a promulgação das EC mencionadas (orçamento impositivo), garantias de sua execução, uma vez que cabia ao Executivo executar ou não determinada emenda com base nos recursos disponíveis no Tesouro Nacional. Assim, a barganha foi modificada, pois o Executivo ainda tem mecanismos, como ordem de preferência de pagamentos.

\footnotetext{
${ }^{1}$ Instituída pelo artigo 166, $\$ 1$ ํㅡ, da Constituição Federal de 1988.

${ }^{2}$ Resolução no 1/1993 do Congresso Nacional.

${ }^{3}$ Resolução no 2/1995 do Congresso Nacional, que também estabeleceu um teto de R \$ 1,5 milhão no valor total das emendas por parlamentar.

${ }^{4}$ Decorrente de tributos, contribuições industriais, de serviços e agropecuárias.
} 
De acordo com Kanayama (2009), a aprovação da lei orçamentária outorga somente a autorização ao Executivo para efetuar determinada despesa, sem impor sua ação. Esse poder pode, ainda, contingenciar emendas às disponibilidades de recursos, conforme previsto na Lei de Responsabilidade Fiscal (LRF). Assim, parece razoável presumir que o Poder Executivo usufrua de fatores que lhe propiciem maior discricionariedade na execução orçamentária e maior força na barganha com o Legislativo, ajudando-o a manter a unidade de sua coalizão.

O modelo teórico apresentado na segunda seção deste estudo propõe uma análise do comportamento dos congressistas com relação às emendas individuais propostas ao orçamento. $\mathrm{O}$ orçamento impositivo não eliminou a discricionariedade do Executivo; apenas limitou sua margem de atuação no estágio de empenho. Desse modo, respeitando-se as normas para o contingenciamento na fase de liquidação, o governo poderia direcionar os recursos a determinados congressistas com base no apoio destes em votações que envolvam interesses do Poder Executivo, conforme representado na Figura 1.

\section{FIGURA 1 AS EMENDAS PARLAMENTARES INDIVIDUAIS (EPI) NO ORÇAMENTO IMPOSITIVO}

Poder Executivo
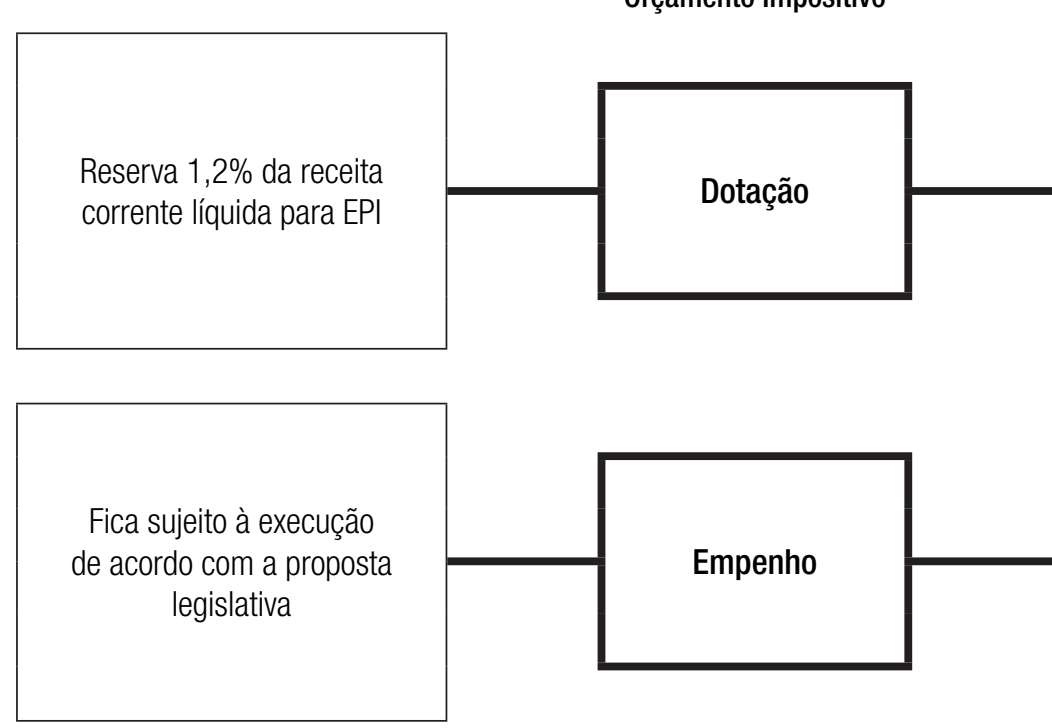

Estágio da Despesa no Orçamento Impositivo
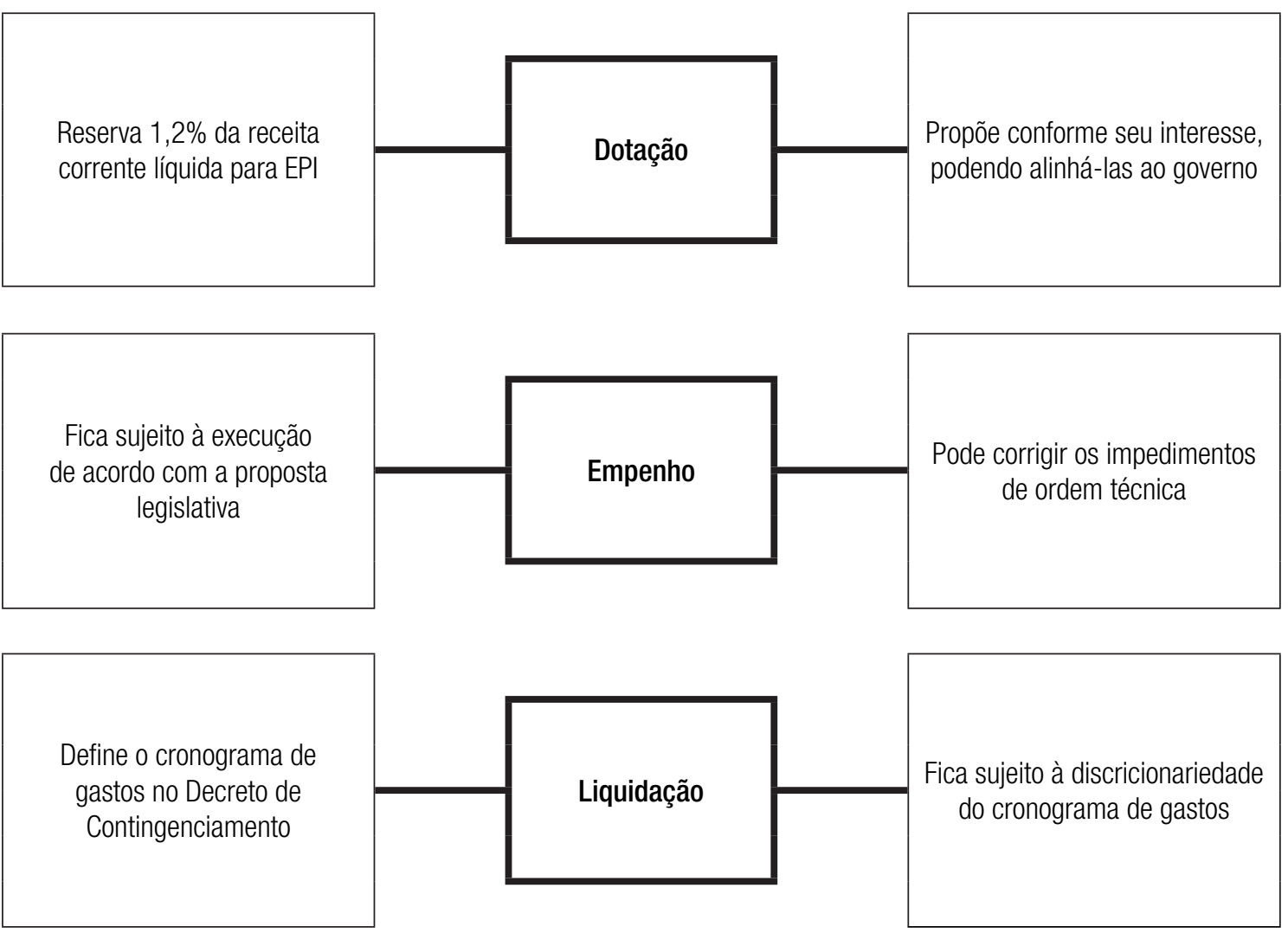

Fonte: Elaborada pelos autores com base em Capellini (2018).
Poder Legislativo

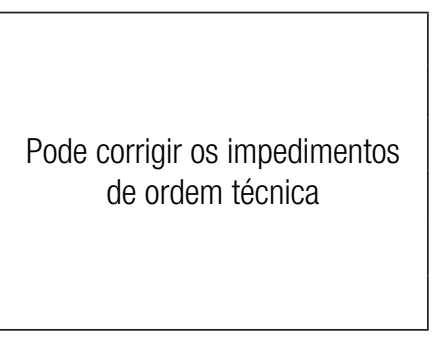
cronog à discricionariedade cronograma de gastos 
A princípio, a garantia do empenho das emendas individuais (exceto por impedimentos técnicos) parece favorecer os congressistas. Contudo, uma vez que a liquidação permanece sujeita à discricionariedade, o que ocorre é apenas uma redução da "sensação de falta de isonomia" por parte dos parlamentares, sem que a igualdade dos valores garantidos para o empenho se reflita em igualdade para a liquidação dos recursos no cronograma de contingenciamento. Além disso, ressalta-se que, se as emendas não forem liquidadas ao término do exercício, ${ }^{5}$ os congressistas estão sujeitos a perder seus empenhos em emendas individuais (que supostamente estariam garantidos pelo $₫ 11$ da EC 86 (2015) referentes a 1,2\% da receita corrente líquida.

Com vistas a ilustrar o fenômeno abordado neste artigo, a Tabela 1 sintetiza a cronologia das despesas de investimento pagas ${ }^{6}$ durante o período estudado. Nota-se que grande parte da despesa orçamentária relativa à conta Investimento é efetivamente paga especificamente no mês de dezembro, ou seja, no último mês do ano, sendo a maior parte desse montante designada como restos a pagar a serem liquidados (classificados como Restos a Pagar Não Processados - RPNP) no ano subsequente.

TABELA 1 DESPESAS DE INVESTIMENTO PAGAS PELO PODER EXECUTIVO (EM R\$ MILHÕES)

\begin{tabular}{|c|cccc}
\hline Anos & \multicolumn{2}{c}{ Mês de pagamento } & Total no ano & $\begin{array}{c}\text { Percentual pago em } \\
\text { dezembro }\end{array}$ \\
\hline 2008 & 5.848 & Dezembro & 8.941 & $35 \%$ \\
2009 & 9.568 & 3.094 & 13.959 & $31 \%$ \\
2010 & 16.053 & 4.391 & 21.512 & $25 \%$ \\
2011 & 11.162 & 5.460 & 16.657 & $33 \%$ \\
2012 & 16.623 & 5.495 & 21.550 & $23 \%$ \\
2013 & 12.742 & 4.927 & 16.927 & $25 \%$ \\
2014 & 15.566 & 4.185 & 19.060 & $18 \%$ \\
2015 & 7.703 & 3.494 & 9.640 & $20 \%$ \\
2016 & 8.043 & 1.937 & 16.826 & $52 \%$ \\
2017 & 11.296 & 8.783 & 18.428 & $39 \%$ \\
\hline
\end{tabular}

Fonte: Elaborada pelos autores a partir de dados da Secretaria do Tesouro Nacional.

Nesse contexto, cumpre-se destacar que um relevante marco institucional para a gestão dos recursos de caixa do Tesouro Nacional foi o Decreto ํo 93.872/1986, vinculado à Lei ํㅡㄴ 4.320/1964, por trazer em seu arcabouço legal o instrumento Restos a Pagar com o intuito de flexibilizar a execução

\footnotetext{
${ }^{5}$ Seriam tratadas como restos a pagar não processados (considerando que o fornecedor/credor tenha cumprido sua obrigação de desempenho), estando sujeitas à escolha discricionária do Executivo para inclusão (ou não) no próximo orçamento (o Decreto no 93.872/1986, que regulamenta o artigo 37 da Lei no 4.320/1964).

${ }^{6} \mathrm{O}$ termo "paga" refere-se ao último estágio de execução da despesa pública (empenho, liquidação e pagamento). Portanto, uma despesa "paga" caracteriza uma despesa "executada".
} 


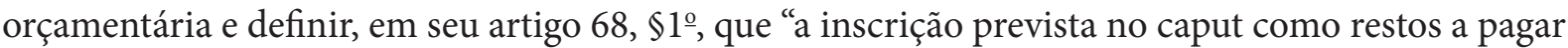
não processados fica condicionada à indicação (também) pelo ordenador de despesas". Isso garante ao ordenador de despesa relativa discricionariedade para a inscrição de RPNP no encerramento do exercício financeiro, salvo empenhos referentes a despesas com diárias, ajuda de custo e suprimento de fundos.

Dessa forma, assume-se como premissa deste estudo que, inicialmente, o Poder Executivo observa a decisão de voto dos parlamentares, principalmente em pautas levadas por ele ao Congresso Nacional, e só então beneficia aqueles dispostos a apoiar a legenda Executiva com a execução de suas parcelas emendadas ao orçamento. O Executivo pode, ainda, favorecer seus apoiadores com uma maior liberação desses recursos em detrimento dos demais membros do Legislativo.

\section{ESTUDOS ANTERIORES SOBRE A FORMAÇÃO E GERENCIAMENTO DE COALIZÕES}

Em seu estudo pioneiro intitulado The theory of political coalitions, Riker (1962) teoriza que a formação de governos de coalizão deveria se dar não por uma grande quantidade de participantes, mas por uma mínima quantidade suficiente para controle, o que garantiria vitória ao chefe de governo em meio às decisões parlamentares. Riker (1962) denominou esta como sendo a “coalizão mínima vencedora”. No Brasil, o pioneirismo sobre assunto surgiu por meio do estudo realizado por Abranches (1988), que cunhou o termo "presidencialismo de coalizão" ao se referir à forma com qual o Executivo interage com o Legislativo.

A análise da produção científica sobre a formação de coalizões sugere ser ainda incipiente a abordagem do tema sob a ótica da barganha política entre os Poderes Executivo e Legislativo na elaboração e na execução orçamentária brasileira. Existe significativa dependência da coalizão para propiciar governabilidade em regimes presidencialistas e multipartidários, como dimensionado no "Índice de Necessidade de Coalizão", que mensura o quanto determinado presidente depende da necessidade de governar por meio de coalizões (Ames, 1995; Chaisty et al., 2014; Raile, Pereira, \& Power, 2011).

O Poder Executivo influencia o modo como votam os congressistas ao escolher estrategicamente quais emendas serão executadas. Pereira e Mueller (2002), ao analisarem 325 votações nominais entre os anos de 1995 a 1998, encontraram evidências que corroboram tal afirmação, assim como Ravanelli, Costa, e Bonacim (2012), os quais avaliaram o comportamento de 134 deputados federais durante 2009 e caracterizaram a relação de barganha política ao constatarem a existência de uma relação positiva entre votos favoráveis ao governo e emendas aprovadas. Ainda no contexto nacional, o estudo de Bertholini e Pereira (2017) discutiu a formação de coalizões nos governos Fernando Henrique Cardoso (FHC), Lula e Dilma e evidenciaram o custo do governo no gerenciamento de sua coalizão, por meio da quantidade total de ministérios e secretarias, gastos totais com emendas e gastos ministeriais totais.

Este estudo procura preencher uma lacuna da literatura ao trazer novas evidências sobre o processo de barganha política entre os Poderes Legislativo e Executivo Federal. Além de prover evidências sobre um período mais amplo e mais recente, o método econométrico empregado nesta análise possibilita corrigir o viés de seleção amostral na amostra aqui analisada.

A próxima seção tratará dos métodos empregados para a análise do fenômeno de barganha política entre os anos de 2000 a 2017, bem como os dados explorados. 


\section{METODOLOGIA E BASE DE DADOS}

Este estudo traz uma abordagem quantitativa, de caráter ontológico objetivista e epistemologia positivista (Ryan, Scapens, \& Theobald, 2002). Em particular, abarcam-se impactos orçamentários ligados ao fenômeno de âmbito quantitativo (quanto ao envolvimento de parte da conta Investimentos do Orçamento) e qualitativo (quanto às características dos parlamentares que propõem as emendas que têm maior aporte de execução).

Os dados referentes ao PLOA aprovada para os anos de 2000 a 2017 foram obtidos com a colaboração da Secretaria de Orçamento Federal (SOF) do Ministério do Planejamento, Desenvolvimento e Gestão, a partir de dois grandes sistemas de dados orçamentários: o Sistema Integrado de Planejamento e Orçamento (Siop) e o Sistema Integrado de Administração Financeira (Siafi). Tais dados foram obtidos por meio do Serviço de Informação ao Cidadão (SIC). Teve-se também apoio do Centro Brasileiro de Análise e Planejamento (Cebrap) para a obtenção de informações ministeriais, e do Centro de Documentação e Informação da Câmara dos Deputados para a obtenção dos dados relativos às características dos parlamentares. ${ }^{7}$

É importante ressaltar que, para este estudo, foi selecionada apenas uma parte das observações disponíveis referentes às emendas parlamentares. Como as emendas coletivas são formadas por dois ou mais parlamentares, observa-se um problema recorrente na base de dados fornecida pela Câmara dos Deputados. Nas variáveis referentes aos valores das emendas (dotação inicial, valor liquidado, empenhado e pago) para as emendas coletivas, consta apenas seu valor total, sem separar os valores correspondentes a cada parlamentar que a compõe. O mesmo ocorre quando se separam as emendas de acordo com sua funcional programática (identificação da emenda), que as classifica de acordo com 17 dígitos, porém sem nenhum dígito identificador do autor da emenda. Em particular, até 2015, as informações disponíveis referem-se à execução do total do orçamento para a funcional programática e não há dados de execução somente da emenda.

Ainda que uma emenda seja individual, ela pode pertencer a uma mesma funcional programática de diferentes parlamentares, porém sem diferenciar a informação de valores para cada um deles. Como isso é recorrente na base de dados utilizada neste estudo, selecionaram-se apenas informações sobre emendas individuais que fossem únicas para determinada funcional programática. Em tal estudo, esse tipo de emenda é denominado "emenda singular". Em contrapartida, há as "emendas plurais", que são emendas coletivas ou não têm a mesma funcional programática.

Para a realização deste estudo, foram utilizadas duas bases de dados envolvendo os anos de 2000 a 2017. A primeira delas contém dados relativos às emendas apresentadas pelos parlamentares; e a segunda base, por sua vez, contém, para cada ano, características dos autores das emendas e de seu comportamento em votações de projetos do Executivo, bem como a situação de suas emendas anexadas ao PLOA.

Com o intuito de verificar a relação entre os votos dos parlamentares aos projetos do Executivo e a execução orçamentária de emendas parlamentares, foi necessário levar em conta um problema estatístico existente em análises desse tipo: o viés de seletividade amostral causado, nesse caso, pela utilização exclusiva de dados sobre emendas parlamentares singulares (conforme já mencionado).

\footnotetext{
${ }^{7}$ Ressalta-se que os testes empíricos realizados não contemplam trocas de partido por parte dos parlamentares, pelo fato de esse fenômeno exceder o escopo do trabalho.
} 
De forma específica, se a apresentação de emendas individuais ou coletivas fosse totalmente aleatória, a estimação de uma regressão simples envolvendo apenas dados de emendas individuais seria não viesada e consistente e, portanto, representativa da população. Contudo, a apresentação de emendas individuais ou coletivas não é um fenômeno aleatório, mas, sim, uma opção dos próprios parlamentares. É possível, por exemplo, que alguns parlamentares optem por propor apenas emendas em conjunto com outros parlamentares da mesma bancada ou, ainda, que em certo período, um determinado parlamentar opte por destinar uma emenda de sua exclusividade para seu reduto eleitoral. Nesse sentido, estimações envolvendo apenas dados das emendas individuais estariam sujeitas ao problema de viés de seleção amostral, fazendo com que os resultados fossem viesados e inconsistentes e deixassem de ser, portanto, representativos da população. Assim, é preciso utilizar um método que permita lidar com este fenômeno.

Heckman (1979) propôs um procedimento de estimações em dois estágios para se corrigir o referido viés. O primeiro estágio envolve a estimação de uma regressão auxiliar por meio da qual se calcula a probabilidade da ocorrência do evento de interesse que, no estudo aqui proposto, é a probabilidade de um parlamentar apresentar uma emenda individual (relativa à probabilidade de ele apresentar uma emenda coletiva). Desse modo, em um primeiro estágio, estima-se uma regressão do tipo probit ${ }^{8}$ em que a variável dependente assume o valor "1", caso o parlamentar tenha apresentado emenda individual, e "0" caso tenha apresentado emenda coletiva. Tal estimação pode ser representada pela equação (1):

$$
\operatorname{Prob}(D=1 \mid Z)=Z \cdot \gamma
$$

Em que é uma variável binária que assume o valor 1, caso a emenda seja individual; e 0, caso seja coletiva. $Z$ representa a matriz de variáveis explicativas; e $\gamma$, o vetor de coeficientes da equação (1).

A partir disso, realiza-se o segundo estágio, que envolve a estimação da equação principal deste estudo. No caso, a variável dependente mensura o valor da emenda individual e o viés de seleção é corrigido incorporando-se a razão inversa de Mills como uma das variáveis explicativas que, por sua vez, é função da probabilidade calculada no primeiro estágio. A equação (2) representa a equação principal (o segundo estágio) do estudo:

$$
E[Y \mid X, D=1]=X \cdot \beta+\lambda \cdot(Z \cdot \gamma)
$$

Em que representa o valor das emendas individuais; , a matriz de variáveis explicativas da equação principal; $\beta$, o vetor de parâmetros associados às variáveis explicativas; e , o parâmetro associado à razão inversa de Mills. Assim, se o parâmetro $\lambda$ for estatisticamente significante, há evidências de viés de seleção amostral. Por sua vez, caso $\lambda$ seja estatisticamente nulo, não há tal viés, e a equação (1) pode ser estimada de forma não viesada e consistente sem a correção via inclusão da razão inversa de Mills como variável explicativa.

Em um primeiro momento, designou-se para o primeiro estágio uma base de dados contendo as emendas parlamentares propostas entre 2000 e 2017, bem como suas características. De todas

\footnotetext{
${ }^{8}$ Assim, assume-se que o termo de erro da estimação segue uma distribuição normal padrão.
} 
as emendas disponíveis, utilizaram-se para análise apenas as emendas consideradas singulares. Em números, foram consideradas 79.923 emendas singulares de um total de 169.235 propostas (entre singulares e plurais) pelos parlamentares.

Dada a ausência de referências que analisem os motivos que levam um parlamentar a apresentar emendas individuais ( $v i s-\grave{a}$-vis as emendas coletivas), as variáveis explicativas do primeiro estágio da abordagem de Heckman (1979) foram definidas com base nas características da amostra explorada. Em primeiro lugar, nota-se que as emendas com destinação (município) específica se mostram predominantemente singulares, enquanto as emendas plurais são, em sua maioria, caracterizadas por não terem uma destinação precisa de recursos especificada em sua apresentação. Em segundo lugar, a maior parte das emendas vincula-se às funções orçamentárias de urbanismo, saúde e lazer. Além disso, procurou-se levar em conta a possibilidade de o alinhamento político com ministros do Governo Federal influenciar a decisão dos parlamentares em apresentar emendas individuais. Dessa forma, o Quadro 1 apresenta as variáveis utilizadas no primeiro estágio.

\section{QUADRO 1 VARIÁVEIS DO PRIMEIRO ESTÁGI0 ${ }^{9}$}

\begin{tabular}{|c|c|}
\hline Variável & Definição \\
\hline Tipo de emenda - variável dependente & 1, se a emenda for singular; 0 , caso contrário \\
\hline Ministério - partido - coligação & $\begin{array}{l}\text { 1, se o parlamentar for filiado a um partido da coligação e destinou sua emenda a } \\
\text { algum ministério cujo controle também é de um dos partidos da coligação (mesmo } \\
\text { que diferente do parlamentar); 0, caso contrário }\end{array}$ \\
\hline Emenda - município & 1, se a emenda for destinada especificamente a um município; 0, caso contrário \\
\hline Emenda - urbanismo & 1, se a emenda for caracterizada na área de despesa em urbanismo; 0, caso contrário \\
\hline Emenda - lazer & 1, se a emenda for caracterizada na área de despesa em lazer; 0, caso contrário \\
\hline Emenda - saúde & 1, se a emenda for caracterizada na área de despesa em saúde; 0, caso contrário \\
\hline Dummies de UF & Dummies para cada Unidade da Federação (UF) da amostra \\
\hline Dummies de ano & Dummies para cada ano da amostra \\
\hline
\end{tabular}

Fonte: Elaborado pelos autores.

Por sua vez, definidas com base tanto na literatura existente quanto nas características da amostra, o Quadro 2 apresenta as variáveis utilizadas no modelo principal (segundo estágio).

\footnotetext{
${ }^{9}$ As dummies de ano têm o objetivo de controlar as estimações por efeitos específicos de cada ano da amostra e comuns a todas as observações, como a ocorrência de choques macroeconômicos ou o fato de em determinado ano ocorrer eleições, por exemplo.
} 


\section{QUADRO 2 VARIÁVEIS DO SEGUNDO ESTÁGI010}

\begin{tabular}{|c|c|c|}
\hline Variável & Definição & Estudos anteriores \\
\hline $\begin{array}{l}\text { Valor liquidado (em logaritmo } \\
\text { natural) - variável dependente }\end{array}$ & $\begin{array}{l}\text { Valor liquidado de todas as emendas de determinado } \\
\text { parlamentar (em logaritmo natural) }\end{array}$ & \\
\hline $\begin{array}{l}\text { Proporção de votos favoráveis } \\
\text { defasada }\end{array}$ & $\begin{array}{l}\text { Proporção de votos favoráveis do parlamentar i a projetos do } \\
\qquad \text { Executivo no ano t-1 }\end{array}$ & Alston e Muller (2001) \\
\hline Proporção liquidada & $\begin{array}{l}\text { Proporção do valor total liquidado de todas as emendas } \\
\text { propostas pelo parlamentar i no ano t }\end{array}$ & - \\
\hline $\begin{array}{l}\text { Presidente/vice-presidente - } \\
\text { comissão }\end{array}$ & $\begin{array}{l}\text { 1, se o parlamentar i for presidente ou vice-presidente de } \\
\text { alguma comissão no ano t; 0, caso contrário }\end{array}$ & - \\
\hline Partido de esquerda & $\begin{array}{l}\text { 1, se a ideologia do partido do parlamentar i for classificada } \\
\text { como de esquerda; } 0 \text {, caso contrário }\end{array}$ & $\begin{array}{c}\text { Pereira e Mueller } \\
\text { (2002); Rodrigues } \\
\text { (2002); Tarouco e } \\
\text { Madeira (2013); Maciel, } \\
\text { Alarcon e Gimenes } \\
\text { (2018) }\end{array}$ \\
\hline Partido de coligação ao governo & $\begin{array}{l}\text { 1, se o partido do parlamentar i pertence à coligação de } \\
\text { governo; } 0 \text {, caso contrário }\end{array}$ & - \\
\hline $\begin{array}{l}\text { Proporção emendas - ministérios } \\
\qquad \text { - coligação }\end{array}$ & $\begin{array}{l}\text { Proporção de emendas que o parlamentar filiado a um } \\
\text { partido da coligação destinou a algum ministério cujo controle } \\
\text { também é de um dos partidos da coligação (mesmo que } \\
\text { diferente do parlamentar) }\end{array}$ & Luz (2017) \\
\hline Proporção emendas - municípios & $\begin{array}{l}\text { Proporção de emendas destinadas especificamente a } \\
\text { municípios }\end{array}$ & - \\
\hline Razão inversa Mills & Razão inversa de Mills (estimada no primeiro estágio) & - \\
\hline Dummies/ano & Dummies para cada ano da amostra & - \\
\hline
\end{tabular}

Fonte: Elaborado pelos autores.

Seguindo o modelo proposto por Heckman (1979), pois neste estudo o primeiro estágio conta com um banco de dados diferente daquele do segundo estágio, buscou-se adaptar o modelo em questão. Inicialmente, construíram-se dois bancos de dados: o primeiro, utilizado no primeiro estágio, em que cada observação se refere a uma emenda individual, e o segundo, utilizado no segundo estágio, em que cada observação se refere a um parlamentar, no qual constam variáveis como número de votos favoráveis ao Executivo e à ideologia partidária, entre outras variáveis.

\footnotetext{
${ }^{10}$ Esclarece-se que os valores liquidados das emendas foram transformados em logaritmo neperiano para diminuir a chance de as estimações gerarem erros heterocedásticos, o que violaria um dos pressupostos clássicos do método de regressão linear (como de que os erros são homocedásticos). As estimações do segundo estágio também incluem dummies de ano, conforme explicado na nota de rodapé anterior.
} 
Com base no primeiro banco de dados, estimou-se a equação (1) de tal forma que, para cada observação (emenda), foi calculada a probabilidade de ela ser individual. Em seguida, calculou-se a probabilidade média por parlamentar e, a partir dessa média, finalmente calculada a razão inversa de Mills. Subsequentemente, a partir do segundo banco de dados, estimou-se o modelo principal (equação [2]), por meio dos estimadores MQO, Efeitos Fixos e Efeitos Aleatórios. Em particular, para a seleção do método de estimação mais adequado entre os dois últimos mencionados, utilizou-se o teste de Hausman, que avalia a consistência dos dois estimadores.

\section{RESULTADOS}

Esta seção apresenta os resultados das estimações, descritas no tópico anterior deste artigo, seguindo a metodologia proposta por Heckman (1979). A Tabela 2 mostra os resultados do primeiro estágio separadamente por legislatura.

\section{TABELA 2 RESULTADOS DO PRIMEIRO ESTÁGIO}

\begin{tabular}{|c|c|c|c|c|c|c|c|c|c|c|}
\hline \multirow{3}{*}{ Variável explicativa } & \multicolumn{10}{|c|}{ Legislaturas } \\
\hline & \multicolumn{2}{|c|}{$51^{\underline{a}}$} & \multicolumn{2}{|c|}{$52^{\mathrm{a}}$} & \multicolumn{2}{|c|}{$53^{\underline{a}}$} & \multicolumn{2}{|c|}{$54^{\mathrm{a}}$} & \multicolumn{2}{|c|}{$55^{\mathrm{a}}$} \\
\hline & Coef. & $\mathrm{p}$-valor & Coef. & p-valor & Coef. & $\mathrm{p}$-valor & Coef. & p-valor & Coef. & p-valor \\
\hline $\begin{array}{l}\text { Ministério - partido - } \\
\text { coligação }\end{array}$ & 0,212 & 0,000 & 0,256 & 0,000 & 0,212 & 0,000 & 0,461 & 0,000 & 0,360 & 0,000 \\
\hline Emenda - município & 1,863 & 0,000 & 1,823 & 0,000 & 1,683 & 0,000 & 1,535 & 0,000 & 1,791 & 0,000 \\
\hline Emenda - urbanismo & $-0,404$ & 0,000 & $-0,669$ & 0,000 & $-0,594$ & 0,000 & $-0,314$ & 0,000 & $-0,387$ & 0,000 \\
\hline Emenda - lazer & 0,349 & 0,000 & 0,083 & 0,016 & $-0,164$ & 0,000 & $-0,131$ & 0,000 & $-0,239$ & 0,000 \\
\hline Emenda - saúde & $-0,116$ & 0,000 & $-0,464$ & 0,000 & $-0,380$ & 0,000 & $-0,957$ & 0,000 & $-0,586$ & 0,000 \\
\hline Observações & \multicolumn{2}{|c|}{26.925} & \multicolumn{2}{|c|}{33.833} & \multicolumn{2}{|c|}{38.310} & \multicolumn{2}{|c|}{42.754} & \multicolumn{2}{|c|}{27.413} \\
\hline Pseudo- $R^{2}$ & \multicolumn{2}{|c|}{0,328} & \multicolumn{2}{|c|}{0,361} & \multicolumn{2}{|c|}{0,279} & \multicolumn{2}{|c|}{0,274} & \multicolumn{2}{|c|}{0,302} \\
\hline
\end{tabular}

Notas: as estimações_foram obtidas por meio do método probit. A variável dependente é uma variável binária que assume o valor 1, caso a emenda seja singular, e 0 caso seja coletiva. O modelo foi controlado por dummies de UF.

Fonte: Elaborada pelos autores.

Conforme os resultados apresentados na Tabela 2, observa-se que o parâmetro associado à variável explicativa Ministério - partido - coligação é positivo e estatisticamente significante em todas as estimações. Este resultado indica que o fato de uma emenda apresentada por determinado parlamentar pertencente à coligação de governo ser destinada a um ministério cujo controle também é de um partido da coligação de governo eleva a probabilidade de tal emenda ser singular (comparativamente a ser coletiva). 
Os parâmetros referentes à variável explicativa Emenda - município também são positivos e estatisticamente significantes em todas as estimações. Esse resultado sugere que a destinação de uma emenda a determinado município eleva a chance de ela ser individual. Isso pode sugerir que a maioria das emendas singulares tem aplicação em determinado município já definida em sua apresentação. Trata-se de um efeito político esperado, pois os parlamentares tendem a destinar emendas para seus currais eleitorais, conforme discutido pela literatura sobre pork barrel (Wilson, 1986; Fukui \& Fukai, 1996; Golden \& Picci, 2008; Pereira \& Orellana, 2009).

Quanto aos coeficientes referentes à finalidade programática da emenda parlamentar, é possível observar que todos os coeficientes associados às variáveis explicativas Emenda - urbanismo e Emenda - saúde são negativos e estatisticamente significantes. Tal fato sugere que emendas destinadas a essas áreas estão menos associadas a emendas individuais. Por sua vez, os coeficientes associados à variável explicativa Emenda - lazer são positivos na 51 e na $52^{\underline{a}}$ legislaturas, o que indica maior probabilidade de ela ser individual caso seja destinada a essa função, mas negativos nas demais legislaturas, assinalando menor probabilidade de ser individual.

Os parâmetros apresentados na Tabela 2 servem para o cálculo da razão inversa de Mills, a ser inserida como variável explicativa do segundo estágio, cujos resultados são apresentados na Tabela 3. Dado que o teste de Hausman ${ }^{11}$ indicou como método mais apropriado o de Efeitos Aleatórios, as análises a seguir foram feitas com base nos resultados obtidos a partir desse método de estimação. A Tabela 3 apresenta os parâmetros associados à cada variável explicativa, ${ }^{12}$ seus respectivos p-valores e o coeficiente de determinação $\left(\mathrm{R}^{2}\right)$.

\section{TABELA $3 \quad$ RESULTADOS DO MODELO PRINCIPAL (SEGUNDO ESTÁGIO)}

\begin{tabular}{lcc} 
Variável explicativa & Coef. & p-valor \\
Proporção de votos favoráveis defasada & 0,268 & 0,088 \\
Proporção liquidada & 2,599 & 0,000 \\
Presidente/vice-presidente - comissão & $-0,002$ & 0,966 \\
Partido de esquerda & 0,203 & 0,000 \\
Partido de coligação ao governo & $-0,160$ & 0,000 \\
Proporção - emendas - ministérios - coligação & 0,036 & 0,702 \\
Proporção - emendas - municípios & 0,538 & 0,000 \\
Razão inversa Mills & $-0,538$ & 0,000 \\
& & \multicolumn{2}{c}{ Continua }
\end{tabular}

\footnotetext{
${ }^{11} \mathrm{O}$ teste de Hausman robusto, ao nível de $5 \%$ de confiança, gerou um p-valor de 0,5081 , indicando como mais adequada (consistente e eficiente) a estimação por efeitos aleatórios.

${ }^{12} \mathrm{O}$ teste $\mathrm{F}$ apresentou Prob $>\mathrm{F}=0,000$, o que classifica o modelo como estatisticamente significante. O teste de Breush-Pagan apresentou Prob $>$ chi2 $=0,000$, rejeitando, assim, a hipótese nula de homocedasticidade. O teste de Wooldridge apresentou Prob $>\mathrm{F}=0,9203$, aceitando-se a hipótese nula de ausência de autocorrelação dos resíduos. O teste de Chow apresentou Prob $>\mathrm{F}=0,000$, indicando o método de dados em painel como sendo preferível ao método de estimação por MQO. O Fator de Inflação da Variância não detectou presença de multicolinearidade em nenhuma das variáveis explicativas do modelo.
} 


\begin{tabular}{lcc} 
Variável explicativa & Coef. & p-valor \\
Constante & 12,130 & 0,000 \\
Observações & 2.718 \\
$\mathrm{R}^{2}$ & 0,428 \\
\hline
\end{tabular}

Notas: a variável dependente é o valor liquidado das emendas em logaritmo natural; a variável explicativa Proporção de votos favoráveis defasada refere-se à proporção de votos do parlamentar favoráveis aos projetos do Poder Executivo no período imediatamente anterior. Os resultados foram obtidos por meio do modelo de efeitos aleatórios. O modelo foi controlado por dummies de ano com o objetivo de controlar as estimações por efeitos específicos de cada ano da amostra.

Fonte: Elaborada pelos autores.

Segundo os resultados das estimações, a principal variável explicativa deste estudo, a proporção de votos do parlamentar favoráveis a projetos do Executivo (do ano anterior à execução de emendas) tem relação positiva e estatisticamente significante a $10 \%$ com o valor executado das emendas parlamentares. Esse resultado sugere que, quanto maior o apoio de um parlamentar ao Executivo em votações no Congresso (em um dado ano), maior será o montante executado de suas emendas (no ano seguinte). Desse modo, isso caracteriza o fenômeno da barganha política na execução orçamentária federal. Conforme teorizado neste artigo, há resultados que corroboram a hipótese de que o Executivo se utiliza da discricionariedade na execução das emendas para o gerenciamento de sua coalizão. Segundo os resultados obtidos, um aumento de 10 pontos percentuais de votos parlamentares favoráveis aos projetos do Executivo (em determinado ano) eleva, em média, o valor liquidado de suas emendas em quase três pontos percentuais no ano subsequente.

A respeito da variável que define a proporção dos valores das emendas liquidadas com relação ao que foi apresentado por seus autores parlamentares (Proporção liquidada), inserida no modelo como variável de controle, nota-se que seu coeficiente é positivo e estatisticamente significante a 5\%. Esse resultado sugere que o valor liquidado das emendas propostas por determinado parlamentar está intimamente ligado à proporção liquidada do total de emendas propostas, de tal forma que, quanto maior for essa proporção, maior será o valor total executado.

Com relação ao exercício de liderança no Congresso e sua influência na execução de emendas, o coeficiente associado à variável que define se o parlamentar foi presidente ou vice-presidente de alguma comissão durante determinado ano (Presidente/vice-presidente - comissão) não apresentou significância estatística. Isso sugere, portanto, que o fato de um parlamentar atuar em altos postos nas comissões do Congresso não exerce efeito sobre o valor executado das emendas de sua autoria.

Ao se analisar o direcionamento ideológico, os resultados sugerem que o fato de um parlamentar ter sido de um partido de ideologia de esquerda (Partido de esquerda) aumentou em, aproximadamente, $20 \%$ o valor executado de suas emendas. Nota-se que o coeficiente associado a tal variável explicativa é positivo e estatisticamente significante a $5 \%$.

Quanto à variável explicativa Partido de coligação ao governo, nota-se um coeficiente negativo e estatisticamente significante. Tal fato sugere que parlamentares pertencentes a partidos da coligação do governo têm um menor valor executado de suas emendas comparativamente a parlamentares filiados a partidos que não fazem parte dela. Apesar de esse resultado ser aparentemente paradoxal, uma possível interpretação do mesmo é que um parlamentar da coligação, por já estar alinhado com o poder Executivo, tem outros mecanismos para viabilizar suas políticas públicas além das emendas, tal que ele pode propor políticas que se materializem já no orçamento, ou seja, antes da proposição 
de emendas. Assim, não haveria oposição desses parlamentares ao terem suas emendas executadas em menor proporção com relação aos parlamentares da oposição.

Analisando-se o efeito da variável explicativa Proporção - emendas - ministérios - coligação, notase que seu coeficiente é positivo, mas estatisticamente não significante. Assim, os resultados sugerem não haver relação entre o valor liquidado da emenda e o fato de um parlamentar pertencer a um partido de coligação e destinar emendas para um ministério cujo ministro também pertence a um partido de coligação.

Os resultados das estimações também sugerem que, quanto maior a proporção de emendas singulares destinadas a municípios predefinidos, maior o valor de suas liquidações, pois o coeficiente associado à variável Proporção - emendas - municípios é positivo e estatisticamente significante.

Inserido nas estimações com o objetivo de torná-las não viesadas e consistentes, o coeficiente associado à razão inversa de Mills é estatisticamente significante a 1\%. Esse resultado sugere a existência de viés de seletividade amostral, ou seja, que a decisão dos parlamentares em apresentar emendas individuais (relativamente à decisão de apresentar emendas coletivas) não é aleatória. Conforme mencionado, o controle pelo viés de seletividade amostral é uma das principais contribuições deste estudo, dado que a literatura existente até então ignora tal efeito.

Para fins de comparação, os resultados apresentados na Tabela 4 se referem a um modelo alternativo em que a variável dependente é substituída pela quantidade de emendas liquidadas, além de se abandonar a correção do viés de seletividade amostral. Entre outros, nota-se que a não inclusão da razão inversa de Mills faz com que o coeficiente da principal variável explicativa do modelo, qual seja, a proporção de votos do parlamentar favoráveis ao Executivo, deixe de ser estatisticamente significativo. Logo, estudos que ignorassem a presença do viés de seletividade amostral chegariam a conclusões equivocadas sobre o fenômeno abordado neste estudo.

\section{TABELA 4 RESULTADOS DO MODELO PRINCIPAL SEM CORREÇÃO DO VIÉS DE SELETIVIDADE AMOSTRAL}

\begin{tabular}{|c|c|c|}
\hline Variável explicativa & Coef & p-valor \\
\hline Proporção de votos favoráveis defasada & 0,157 & 0,819 \\
\hline Proporção liquidada & 1,567 & 0,000 \\
\hline Presidente/vice-presidente - comissão & 0,182 & 0,392 \\
\hline Partido de esquerda & 1,045 & 0,000 \\
\hline Partido de coligação ao governo & $-0,011$ & 0,950 \\
\hline Proporção - emendas - ministérios - coligação & 0,465 & 0,249 \\
\hline Proporção - emendas - municípios & 12,304 & 0,000 \\
\hline Constante & 0,952 & 0,073 \\
\hline Observações & \multicolumn{2}{|c|}{2.948} \\
\hline $\mathrm{R}^{2}$ & \multicolumn{2}{|c|}{0,499} \\
\hline
\end{tabular}

Notas: a variável dependente é a quantidade de emendas liquidadas; a variável explicativa Proporção votos favoráveis defasada refere-se à proporção de votos do parlamentar favoráveis aos projetos do poder Executivo no período imediatamente anterior.

Fonte: Elaborada pelos autores. 
Os resultados sugerem que o nível de apoio dos deputados à coalizão governista está relacionado com o aumento das liquidações das emendas, o que corrobora a hipótese de existência de barganha política entre os Poderes Executivo e Legislativo. Para um período ainda sem os eventuais efeitos das práticas de orçamento impositivo (Emenda Constitucional no 86 e Emenda Constitucional no 100), os resultados sugerem que práticas de barganha sustentadas na prática do pork barrel foram replicadas como mecanismo de governabilidade em governos de coalizão.

\section{CONSIDERAÇÕES FINAIS}

Este estudo teve como objeto central analisar a relação entre os Poderes Executivo e Legislativo no processo orçamentário brasileiro. Em particular, o objetivo do estudo foi encontrar evidências da existência do fenômeno de barganha política entre os referidos poderes, bem como caracterizar os parlamentares que optam por participar dessa relação.

A base teórica, fundamentada na Teoria da Formação de Coalizões, não só deu sustentação às hipóteses aqui levantadas, como também elucidou o fenômeno e permitiu abordá-lo sob a perspectiva da controladoria e do planejamento orçamentário aplicados à governança pública. Com base em estimações econométricas que consideraram a presença de viés de seletividade amostral, os resultados obtidos levaram à rejeição da hipótese nula levantada nesta pesquisa, qual seja, que parlamentares que exercem apoio ao Executivo em votações no Congresso não são mais beneficiados em execuções de suas emendas com relação aos demais. Assim, foram encontradas evidências de relação de barganha política entre os Poderes Executivo e Legislativo na execução do orçamento público.

Os resultados obtidos sugerem que o parlamentar com maior aporte de execução de suas emendas singulares ao longo do período de 2000 a 2017 foi aquele que, além de ter exercido apoio ao Executivo por meio de votos favoráveis aos projetos enviados ao Congresso, era de fora da coligação de governo e obteve uma proporção significativa de emendas liquidadas. Além disso, outro resultado importante refere-se ao fato de que os parlamentares mais beneficiados via execução de suas emendas foram aqueles que propuseram emendas singulares destinadas a municípios específicos. De fato, boa parte das emendas que são exclusivas de um parlamentar (emendas individuais) tem uma característica bastante comum: sua destinação explícita a municípios que, provavelmente, foram essenciais para as candidaturas dos respectivos propositores dessas emendas. Isso corrobora a literatura sobre pork barrel.

De modo mais amplo, os resultados do presente estudo indicam que o Poder Executivo tem a importante chance de diferenciar as dotações para a execução das emendas parlamentares de acordo com características dos parlamentares que lhe custaram maior atenção, como ideologia, posição explícita de apoio ou oposição ao governo e a principal delas: o comportamento frente às votações para a implementação de seus projetos e a formação de sua coalizão. Por fim, a respeito de perspectivas para a agenda de pesquisa futura, os autores sugerem que sejam analisadas as eventuais mudanças no processo de barganha entre Executivo e Legislativo frente ao novo contexto de emendas impositivas, proposto tanto pela EC no 86 (2015) quanto pela $E C \mathrm{n}^{-} 100$ (2019). Esta abordagem pode trazer resultados que permitam caracterizar a relação entre tais poderes diante dessas importantes mudanças institucionais. 


\section{REFERÊNCIAS}

Abranches, S. (1988). Presidencialismo de coalizão: o dilema institucional brasileiro. Dados, 31(1), 5-38.

Alston, L. J., \& Mueller, B. (2001). Pork for policy: executive and legislative exchange in Brazil. Journal of Law, Economics, and Organization, 22(1), 87-114.

Ames, B. (1995). Electoral rules, constituency pressures, and pork barrel: bases of voting in the Brazilian Congress. The Journal of Politics, 57(2), 324-343

Bertholini, F., \& Pereira, C. (2017). Pagando o preço de governar: custos de gerência de coalizão no presidencialismo brasileiro. Revista de Administração Pública, 51(4), 528-550.

Capellini, G. A. (2018). Execução de emendas parlamentares e orçamento impositivo brasileiro (Tese de Doutorado). Universidade de São Paulo, Ribeirão Preto, SP.

Chaisty, P., Cheeseman, N., \& Power, T. (2014). Rethinking the 'presidentialism debate': conceptualizing coalitional politics in cross-regional perspective. Democratization, 21(1), 72-94.

Cheibub, J. A., Przeworski, A., \& Saiegh, S. M. (2004). Government coalitions and legislative success under presidentialism and parliamentarism. British Journal of Political Science, 34(4), 565-587.

Constituição da República Federativa do Brasil de 1988. (1988). Constituição promulgada em 5 de outubro de 1988, Brasília, DF.

Decreto $n^{\circ}$ 93.872, de 23 de dezembro de 1986. (1986). Dispõe sobre a unificação dos recursos de caixa do Tesouro Nacional, atualiza e consolida a legislação pertinente e dá outras providências. Recuperado de http://www.planalto.gov.br/ccivil_03/decreto/ d93872.htm

Emenda constitucional $n^{\circ} 86$ de 17 de março de 2015. (2015). Altera os arts. 165, 166 e 198 da Constituição Federal, para tornar obrigatória a execução da programação orçamentária que especifica. Recuperado de http://www.planalto.gov. br/cci-vil_03/constituicao/Emendas/Emc/emc86. htm

Emenda constitucional $n^{\circ} 100$ de 26 de junho de 2019. (2019). Altera os arts. 165 e 166 da Constituição Federal para tornar obrigatória a execução da programação orçamentária proveniente de emendas de bancada de parlamentares de Estado ou do Distrito Federal. Recuperado de http://www. planalto.gov.br/ccivil_03/constitui-cao/emendas/ emc/emc100.htm

Figueiredo, A. C., \& Limongi, F. D. M. P. (2006). Poder de agenda na democracia brasileira: desempenho do governo no presidencialismo pluripartidário. Reforma política: lições da história recente. Rio de Janeiro, RJ: FGV.

Fukui, H., \& Fukai, S. N. (1996). Pork barrel politics, networks, and local economic development in contemporary Japan. Asian Survey, 36(3), 268-286.

Giacomoni, J. (2008). Orçamento público. São Paulo, SP: Atlas.

Golden, M. A., \& Picci, L. (2008). Pork-barrel politics in postwar Italy, 1953-94. American Journal of Political Science, 52(2), 268-289.

Gontijo, V. (2010). Orçamento impositivo, contingenciamento e transparência. Cadernos Aslegis, 39, 61-72.

Greggianin, E., \& Silva, J. R. P. (2015). O regime do orçamento impositivo das emendas individuais disposições da Emenda Constitucional no 86, de 2015, e da LDO 2015 (Estudo Técnico Conjunto n ${ }^{\circ}$ 1, de 2015). Brasília, DF: Consultoria de Orçamento e Fiscalização Financeira da Câmara dos Deputados e Consultoria de Orçamentos, Fiscalização e Controle do Senado Federal.

Heckman, J. J. (1979). Sample selection bias as a specification error. Econometrica, 47(1), 153-161

Kanayama, R. L. (2009). A ineficiência do orçamento público impositivo. Revista de Direito Público da Economia, 7(28), 127-144.

Kang, W. (2018). The past is long-lasting: Park Chung Hee nostalgia and voter choice in the 2012 Korean presidential election. Journal of Asian and African Studies, 53(2), 233-249.

Lei $n^{\circ}$ 4.320, de 17 de março de 1964. (1964). Estatui Normas Gerais de Direito Financeiro para elaboração e controle dos orçamentos e balanços da União, dos Estados, dos Municípios e do Distrito Federal. Recuperado de http://www.planalto.gov.br/ ccivil_03/leis/14320.htm 
Lima, E. M., \& Viana, P. R. N. (2016). As relações entre o Executivo e o Legislativo na elaboração do orçamento brasileiro: considerações sobre a emenda constitucional 86/2015. Revista de Direito Tributário e Financeiro, 2(2), 199-220.

Limongi, F., \& Figueiredo, A. (1998). Bases institucionais do presidencialismo de coalizão. Lua Nova: Revista de Cultura e Política, 44, 81-106.

Luz, J. H. (2017). Política ministerial: as emendas individuais orçamentárias no presidencialismo de coalizão brasileiro (Tese de Doutorado). Universidade de São Paulo, São Paulo, SP.

Maciel, A. P. B., Alarcon, A. O., \& Gimenes, E. R. (2018). Partidos políticos e espectro ideológico: parlamentares, especialistas, esquerda e direita no Brasil. Revista Eletrônica de Ciência Política, 8(3), 72-88.

Martins, U. L. (2016). Orçamento impositivo brasileiro: reflexão sobre os avanços e as limitações decorrentes da Emenda Constitucional n. 86/2015. Revista de Direito Tributário e Financeiro, 2(2), 382-398.

Pereira, C. (2000). What are the conditions for the presidential success in the Legislative arena? The Brazilian electoral connection (Tese de Doutorado). New School for Social Research, Nova York, NY.

Pereira, C., \& Mueller, B. (2002). Comportamento estratégico em presidencialismo de coalizão: as relações entre Executivo e Legislativo na elaboração do orçamento brasileiro. Dados, 45(2), 265-301.

Pereira, C., \& Orellana, S. (2009). Hybrid political institutions and governability: the budgetary process in Brazil. Journal of Politics in Latin America, 1(3), 57-79.

Raile, E. D., Pereira, C., \& Power, T. J. (2011). The executive toolbox: Building legislative support in a multiparty presidential regime. Political Research Quarterly, 64(2), 323-334.

Ravanelli, R., Costa, D. R. M., \& Bonacim, C. A. G. (2012). Indicativos da existência de barganha no processo orçamentário brasileiro. In Anais do Congresso USP de Controladoria e Contabilidade, Ribeirão Preto, SP.

Riker, W. (1962). The theory of political coalitions. New Haven, CO: Yale University Press.

Rodrigues, L. M. (2002). Partidos, ideologia e composição social: um estudo das bancadas partidárias na Câmara dos Deputados. São Paulo, SP: Edusp.

Ryan, B. \& Scapens, R. W., \& Theobald, M. (2002). Research method and methodology in Finance and Accounting. Londres, UK: Thomson.

Scartascini, C.; Crain, W. M. (2001). The size and composition of government spending in multi-party systems. In Proceedings of Public Choice Society Conference, San Antonio, Texas.

Santos, F. (2002). Partidos e comissões no presidencialismo de coalizão. Dados, 45(2), 237-264.

Tarouco, G. S.; Madeira, R. M. (2013). Partidos, programas e o debate sobre esquerda e direita no Brasil. Revista de Sociologia e Política, 21(45), 149165.

Weingast, B. R., Shepsle, K. A., \& Johnsen, C. (1981). The political economy of benefits and costs: A neoclassical approach to distributive politics. Journal of Political Economy, 89(4), 642-664.

Wilson, R. K. (1986). An empirical test of preferences for the political pork barrel: District level appropriations for river and harbor legislation, 1889-1913. American Journal of Plitic ${ }^{1}$ al Science, 30(4), 729-754 


\section{Luis Henrique Teixeira Graton}

https://orcid.org/0000-0003-3076-5197

Mestre em Controladoria e Contabilidade pela Universidade de São Paulo e professor da Faculdade de Filosofia, Ciências e Letras de Ituverava-SP. E-mail: lhtgraton@gmail.com

\section{Carlos Alberto Grespan Bonacim}

https://orcid.org/0000-0003-0347-9419

Doutor em Controladoria e Contabilidade pela Universidade de São Paulo e professor da FEA-RP/USP.

E-mail: carlosbonacim@usp.br

\section{Sérgio Naruhiko Sakurai}

https://orcid.org/0000-0002-7515-0340

Doutor em Economia pela Universidade de São Paulo e professor da FEA-RP/USP. E-mail: sakurai@usp.br 